\title{
Who Benefits from Building Insurance Groups? A Welfare Analysis of Optimal Group Capital Management
}

\author{
Sebastian Schlütter and Helmut Gründl \\ Faculty of Economics and Business Administration, Goethe-Universität Frankfurt am Main, International \\ Center for Insurance Regulation, Grüneburgplatz 1, Frankfurt/Main 60323, Germany.
}

This paper compares the shareholder-value-maximising capital structure and pricing policy of insurance groups against that of stand-alone insurers. Groups can utilise intra-group risk diversification by means of capital and risk transfer instruments. We show that using these instruments enables the group to offer insurance with less default risk and at lower premiums than is optimal for stand-alone insurers. We also take into account that shareholders of groups could find it more difficult to prevent inefficient overinvestment or cross-subsidisation, which we model by higher dead-weight costs of carrying capital. The trade-off between risk diversification on the one hand and higher dead-weight costs on the other can result in group-building being beneficial for shareholders but detrimental for policyholders.

The Geneva Papers (2012) 37, 571-593. doi:10.1057/gpp.2012.29

Keywords: insurance groups; insurer default risk; insurance pricing; consumer protection

\section{Introduction}

In today's insurance markets, insurers commonly constitute one entity of a larger financial group. It is therefore important for insurance risk managers, regulators and policymakers to understand the specifics of group risk management, shareholder incentives for group-building, and the resulting welfare effects. A key issue for a financial group is the risk diversification among its subsidiaries. Diversification effects at the group level may arise if the subsidiaries' risk profiles are not perfectly positively correlated and the subsidiaries do not all fail at the same time. To utilise risk diversification, the group could implement a system of capital and risk transfer instruments, such as intra-group reinsurance contracts, guarantees, or profit and loss transfer agreements. Filipović and Kupper ${ }^{1}$ analyse how combinations of these instruments are best arranged so as to minimise the group's required equity capital.

According to Modigliani and Miller, ${ }^{2}$ the amount of equity capital that a firm holds is irrelevant for the firm value as long as there are no market imperfections, such as

\footnotetext{
${ }^{1}$ Filipović and Kupper (2008).
} 
financial distress costs or frictional costs related to holding equity capital. For insurance companies, there are several types of market imperfections that influence an insurer's optimal capital structure. On the one hand, insurance buyers are generally risk-averse and might face high costs for diversifying insurer default risk. ${ }^{3}$ Therefore, their willingness-to-pay for insurance will decrease with the insurer's default risk level. This decrease is an insurance-specific type of financial distress cost that provides the insurer with an incentive to hold high levels of equity and thus lower the default risk. On the other hand, insurers might face frictional costs of holding equity capital, resulting from taxation, agency issues or regulatory constraints. The model of Rees et al. ${ }^{4}$ shows that an insurer will hold sufficient equity to avoid any default risk if policyholders can observe the safety level and if holding equity capital does not go along with frictional costs. Other articles on insurance capital structure theory argue that an insurer's optimal equity level solves the trade-off between the incentives resulting from the demand side and frictional costs. ${ }^{5}$ Besides raising equity funds, insurers can also accumulate capital by raising insurance premiums. Therefore, optimal insurance pricing might be strongly affected by frictional costs of equity capital as well. ${ }^{6}$ However, these models focus solely on stand-alone insurers and do not tackle the question of how intra-group capital and risk transfer instruments will influence the optimal equity position of insurance groups, the capital allocation among the subsidiaries as well as optimal insurance pricing in the group case. Since the group entities could fail independently of the rest of the group, they can be provided with different safety levels.

In this paper, we set up a holistic model similar to $Z_{\text {anjani }}{ }^{7}$ and Schlütter, ${ }^{6}$ but focus on an - albeit simplified - insurance group. Our model allows us to investigate how the group will utilise risk diversification in pursuit of shareholder value maximisation. When deciding on the optimal equity capital position and the insurance premium, the insurer anticipates the consequences for insurance demand that would decrease for higher default risk levels. The optimal capital structure is therefore determined by financial distress costs. Our model also incorporates dead-weight costs of equity by means of a proportional carrying charge on the insurer's equity. ${ }^{8}$ Our model illustrates that the group organises the capital allocation among subsidiaries according to the default sensitivity of insurance demand and the profitability of the insurance portfolio. In contrast to a purely arithmetical capital allocation to an insurance firm's lines of business, ${ }^{9}$ capital allocation to the subsidiaries of a group has direct consequences for the subsidiaries' balance sheets and their safety levels. The intra-group risk diversification has three effects: (1) the group overall holds less equity capital than stand-alone insurers, and yet, (2) including the capital and risk

\footnotetext{
2 Modigliani and Miller (1958).

${ }^{3}$ Merton (1997), Froot (2007).

${ }^{4}$ Rees et al. (1999).

${ }^{5}$ Cummins and Sommer (1996), Cummins and Danzon (1997), Zanjani (2002), Froot (2007), Schlütter (2011).

${ }^{6}$ Schlütter (2011).

${ }^{7}$ Zanjani (2002).

${ }^{8}$ Zanjani (2002), Froot (2007), Schlütter (2011).

${ }^{9}$ Myers and Read (2001), Ibragimov et al. (2010).
} 
transfer, the group subsidiaries have higher safety levels than stand-alone insurers, and (3) optimal insurance premiums are lower in the group than they are for the stand-alone insurers since the dead-weight costs of equity are less. Thus, groupbuilding has positive welfare effects for policyholders as well as for shareholders: policyholders benefit due to the reduction of counter-party default risk as well having to pay lower insurance premiums; shareholder value increases because the insurer is able to sell more insurance contracts.

However, according to agency theory, financial groups also suffer the disadvantage of being more complex and opaque than independent smaller entities. Therefore, it is more difficult for shareholders to control the group management and avoid inefficient over-investments or cross-subsidisation within the group. ${ }^{10}$ The empirical literature finds a substantial reduction of shareholder value in widely diversified groups, which is frequently explained by intensified agency conflicts and denoted as a "conglomerate discount". 11

We incorporate this opaqueness problem into our analysis by allowing for different carrying charges of holding equity in the stand-alone case and in the group case. Group-building thus has an advantage and a disadvantage from the perspective of shareholders: on the one hand, the group has access to capital and risk transfer instruments and can ensure solvency by holding less equity than stand-alone insurers. On the other hand, the intensified agency conflict means that the group faces higher frictional costs of holding equity capital. Our numerical examples demonstrate that in situations in which the group faces significantly higher frictional costs than standalone insurers, the group will opt for lower safety levels and higher premiums than the stand-alone insurers.

Our paper also analyses the consequences of group-building for the welfare of shareholders and policyholders. To this end, we measure the welfare of policyholders using the consumer surplus. We identify situations in which shareholders can increase their value through group-building while policyholder welfare is decimated. We find that this situation is highly likely, especially if insurers have little self-interest for holding equity, for example because demand is weakly sensitive to price and/or insurer default risk. To avoid an increase in default rates and the corresponding welfare reduction, regulators should explicitly monitor the group's equity capital levels under these conditions.

The remainder of this paper is organised as follows. The next section takes a look at the relevant literature and situates this paper within this body of work. The section after that presents the model framework and the optimal capital structure and pricing strategy for the stand-alone insurer. The section following deals with the optimal capital allocation and pricing strategy for a group and compares it to the results for the stand-alone case. The subsequent section analyses the group's strategy with consideration of a group-specific carrying charge and provides a welfare analysis. The

\footnotetext{
${ }^{10}$ Amihud and Lev (1981), Jensen (1986), Aron (1988), Jensen and Murphy (1990), Stulz (1990) and Rotemberg and Saloner (1994).

${ }^{11}$ Berger and Ofek (1995), Cummins et al. (2003), Laeven and Levine (2007), Schmid and Walter (2009), Berry-Stölzle et al. (2011).
} 
penultimate section discusses the results in light of empirical findings and derives policy implications. The last section concludes.

\section{Literature overview}

To investigate the consequences of insurance group-building, we combine the methods and arguments of three streams of the literature.

The first line of reasoning addresses the incorporation of capital and risk transfer instruments into the solvency assessment and risk management of insurance groups. On the background of the Swiss Solvency Test, Keller ${ }^{12}$ and Luder ${ }^{13}$ discuss how these instruments are taken into account when defining the group's solvency capital requirements. Filipovic and Kupper ${ }^{1}$ optimise the structure of capital and risk transfer instruments (CRTI) with the objective of minimising the group's required capital, which is defined by convex risk measures. According to financial theory, the risk reduction inherent in the diversification effect implies a reduction of shareholders' limited liability protection, an increase in the market value of debt and therefore a value transfer from shareholders to debt-holders. ${ }^{14}$ Gatzert and Schmeiser ${ }^{15}$ transfer this argumentation to an insurance context and explain that group-building will lead to a value transfer from shareholders to policyholders if the group's capital structure is fixed. However, a fair situation can be restored by adjusting the initial equity levels.

In the context of stand-alone insurance companies, several articles stress the meaning of frictional costs, for example corporate taxation or agency issues, for insurance pricing and insurer safety levels. On the basis of option pricing theory, Doherty and Garven ${ }^{16}$ determine fair insurance prices with a fixed safety level and by incorporating corporate taxation. This has been developed further in several directions, including reinsurance pricing, ${ }^{17}$ multi-line insurance firms, ${ }^{18}$ jump diffusion risk processes, ${ }^{19}$ or endogenous insurer default risk. ${ }^{20}$

Furthermore, agency theory stresses that diversified conglomerates might be subject to more severe agency problems than specialised entities, for example because shareholders have limited capabilities to avoid inefficient misallocations of capital. ${ }^{21}$ Freixas et al. $^{22}$ show that diversification in integrated financial conglomerates can procure higher incentives for excessive risk-taking than stand-alone firms, and thus

12 Keller (2007)

13 Luder (2007).

${ }^{14}$ Mansi and Reeb (2002), Ammann and Verhofen (2006).

15 Gatzert and Schmeiser (2011).

${ }^{16}$ Doherty and Garven (1986).

${ }^{17}$ Gründl and Schmeiser (2002).

18 Phillips et al. (1998), Myers and Read (2001), Gründl and Schmeiser (2007).

19 Gatzert and Schmeiser (2008).

${ }^{20}$ Cummins and Danzon (1997), Gründl and Schmeiser (2002), Zanjani (2002), Froot (2007), Yow and Sherris (2008), Schlütter (2011).

${ }^{21}$ Aron (1988), Stulz (1990), Rotemberg and Saloner (1994).

${ }^{22}$ Freixas et al. (2007). 
destroy welfare. The authors argue that diversified financial conglomerates have less access to deposit insurance than more specialised firms, which could lead to a discount of shareholder value. Their model also incorporates a market-financed intermediary (MFI), which shall represent insurance or securities firms; however, by assuming that the MFI's bondholders are perfectly informed and risk neutral, their model cannot provide implications for insurance regulators.

\section{Stand-alone insurance company}

We start our analysis with the stand-alone insurance company, presenting our solutions analytically in this context and providing insight into the basic mechanics of our model.

\section{Model set-up}

We consider a group of consumers who can purchase insurance to cover homogeneous future risks. Policyholders face the risk of insurer default; however, they have ex ante information about this risk (provided by, e.g. rating agencies or brokers) and take it into account when making purchase decisions. The number of concluded contracts depends on the insurance premium as well as on the insurer's safety level. The insurer decides on the shareholder-value-maximising combination of its equity capital and insurance premium by taking demand reaction into account.

We formulate the model in a one-period framework. At time 0 , shareholders endow the company with equity in the amount of $K$. Due to frictional costs, such as corporate taxes or agency problems, a proportional fraction of $\tau$ is lost. Also at time 0 , the collective of $y$ policyholders pays the insurance premium $p$. In total, the insurer's initial assets are comprised of $A_{0}=(1-\tau) K+y p$. The time 0 value of liabilities is given by $L_{0}=y \mu$, where $\mu$ measures the time value of each policyholder's claims. At time 1 , policyholders report claims in the amount of $L_{1}$. They can be indemnified with the insurer's available assets, $A_{1}$. Due to the randomness of insurance claims and investment risk, $A_{1}$ and $L_{1}$ are stochastic and modelled by random variables. ${ }^{23}$ Policyholders receive in total $\min \left\{A_{1}, L_{1}\right\}$. Shareholders receive the final equity, or maintain their limited liability in the event of insolvency; in total they receive $\max \left\{A_{1}-L_{1}, 0\right\}$. Shareholders have access to arbitrage-free financial markets and evaluate future payoffs under the risk-neutral probability measure $\mathbb{Q}$. Hence, the net shareholder value (SHV) can be formulated as

$$
S H V=\exp (-r) \mathbb{E}_{\mathbb{Q}}\left[\max \left\{A_{1}-L_{1}, 0\right\}\right]-K,
$$

with $r$ the risk-free interest rate. We denote shareholders' default put option by $D P O=\exp (-r) \mathbb{E}_{\mathbb{Q}}\left[\max \left\{L_{1}-A_{1}, 0\right\}\right]$, and the default ratio by $d r=D P O / L_{0}$. Thus, we can rewrite $S H V$ as

\footnotetext{
${ }^{23}$ Throughout the paper, we assume that the stochasticity of $A_{1} / A_{0}$ and $L_{1} / L_{0}$ is exogenous and not subject to the insurer's decision-making.
} 


$$
\begin{aligned}
S H V & =A_{0}-L_{0}+D P O-K \\
& =y \cdot[p-\mu(1-d r)]-\tau K .
\end{aligned}
$$

In accordance with Cummins and Danzon, ${ }^{24}$ Yow and Sherris, ${ }^{25}$ and Schlütter, ${ }^{6}$ we consider the default ratio as the quality measure for insurer default risk and assume insurance demand to be a two-parametric function $y(d r, p)$. The standalone insurer's optimisation problem is completely defined by

$$
\left(P_{1}\right)\left\{\begin{array}{l}
S H V=y(d r, p) \cdot[p-\mu(1-d r)]-\tau K \rightarrow \max _{K, p} \\
d r=\exp (-r) \mathbb{E}_{\mathbb{Q}}\left[\max \left\{L_{1}-A_{1}, 0\right\}\right] / L_{0} \\
A_{0}=(1-\tau) K+y(d r, p) p \\
L_{0}=y(d r, p) \mu
\end{array}\right.
$$

\section{Optimal solution}

Solution of the SHV-maximisation problem $\left(P_{1}\right)$ can be presented analytically. To this end, we utilise the equation for initial assets, $A_{0}=(1-\tau) K+y p=s y \mu$, where $s=A_{0} / L_{0}$ is the initial asset-liability ratio. Furthermore, we assume that there is a bijective relation between the default ratio $d r$ and the asset-liability ratio $s .{ }^{26}$ Such a relation exists, for example, if asset and liability risks are normally or lognormally distributed, ${ }^{27}$ or if liabilities follow a geometric Brownian motion and a jump diffusion process. ${ }^{28} \mathrm{We}$ denote the relation between $s$ and $d r$ by $s=s(d r, \Sigma)$, where $\Sigma$ is the set of parameters of the asset and liability risk distributions. For a given default ratio $d r$, the optimal equity-premium combination is given by: ${ }^{29}$

$$
\begin{gathered}
K^{*}(d r)=y \cdot\left[\mu \cdot s(d r, \Sigma)-\mu \cdot(1-d r)-\frac{1}{1-\tau} \cdot \frac{y}{-y_{p}}\right], \\
p^{*}(d r)=\mu \cdot(1-d r)+\tau \cdot \frac{K^{*}(d r)}{y}+\frac{1}{1-\tau} \frac{y}{-y_{p}} .
\end{gathered}
$$

${ }^{24}$ Cummins and Danzon (1997).

${ }^{25}$ Yow and Sherris (2008).

${ }^{26}$ In other words, the default ratio can be expressed as a function in $s$ which is invertible for $s>1$. Hence, we can also express the asset-liability ratio $s$ that corresponds to the default ratio $d r$ by a function $s(d r)$.

${ }^{27}$ Myers and Read (2001, pp. 576-578).

${ }^{28}$ Cummins (1988, p. 831); Gatzert and Schmeiser (2008, p. 54).

${ }^{29}$ The optimal premium $p^{*}(d r)$ is determined by the first-order condition of SHV-maximisation (see Eq. (2)). As both the default ratio and the asset-liability ratio are fixed, we can deduce the corresponding equity capital $K^{*}(d r)$ from the identified premium. Formally, the derivation is given by Schlütter (2011, p. 9). 
Eq. (4) shows that the optimal premium has three components: (1) the time 0 value of the payoff to policyholders, (2) a premium loading for the frictional costs of equity, and (3) a profit loading. Inserting $p^{*}(d r)$ into Eq. (2) gives us the SHV per contract:

$$
\frac{S H V}{y}=\frac{1}{1-\tau} \frac{y}{-y_{p}}
$$

Hence, the profit loading on the premium, as well as the shareholder value, will converge to zero if demand becomes perfectly price elastic. To this point, we have assumed a fixed default ratio, which is realistic if the insurer faces regulatory solvency requirements and has no incentive to hold additional capital. According to empirical studies, ${ }^{30}$ insurers typically achieve optimal safety levels determined by insurance buyer preferences. In our model, the optimality condition for $d r$ is given by: ${ }^{31}$

$$
\mu-\tau \cdot \mu \cdot\left(1+\frac{\partial s}{\partial d r}\right)=\frac{y_{d r}}{y_{p}}
$$

The left-hand side of Eq. (6) reflects that shareholders derive two benefits from a marginal increase of the default ratio achieved by holding less equity: greater limited liability protection and lower frictional costs of equity. The right-hand side of the equation represents the corresponding costs: fewer insurance contracts will be purchased and the insurer therefore collects less profit loadings. In total, the insurer will hold sufficient capital to ensure a low default ratio if insurance demand reacts strongly to default risk and weakly to price, and if frictional costs are low.

\section{Insurance group}

We next investigate the optimal capital allocation and pricing strategy of an insurance group. For convenience, we consider a group consisting of a holding company and two direct 100 per cent subsidiaries, $a$ and $b$. The subsidiaries are insurers with distinct groups of policyholders. The insurance premium at subsidiary $i \in\{a, b\}$ is denoted by $p^{(i)}$ and the default ratio by $d r^{(i)}$. As the policyholders are contracting with the subsidiary (and not the group), insurance demand depends on the subsidiary's safety level, and is modelled by $y^{(i)}\left(d r^{(i)}, p^{(i)}\right)$. In the following, we initially define intra-group capital transfers and analyse their influence on the subsidiary default risk. We then investigate how the group optimises its capital allocation and insurance pricing policy.

\section{Intra-group risk transfer}

On the basis of Filipović and Kupper, ${ }^{1}$ we model intra-group risk diversification by capital-and-risk transfers that may take place at time 1. Furthermore, we assume that the group can fully exploit risk diversification among the subsidiaries: ${ }^{32}$ if subsidiary $a$

\footnotetext{
${ }^{30}$ Cummins and Danzon (1997), Phillips et al. (1998).

${ }^{31}$ Schlütter (2011, p. 11).
} 
does not have sufficient assets at time $1\left(A_{1}^{a}<L_{1}^{a}\right)$, available assets from subsidiary $b$ will be transferred to $a$. Formally, the capital transfer from $b$ to $a$ can be denoted by

$$
Z_{1}^{b \rightarrow a}=\min \left\{\max \left\{L_{1}^{a}-A_{1}^{a} ; 0\right\} ; \max \left\{A_{1}^{b}-L_{1}^{b} ; 0\right\}\right\} .
$$

In turn, the capital transfer from $a$ to $b$ is given by

$$
Z_{1}^{a \rightarrow b}=\min \left\{\max \left\{L_{1}^{b}-A_{1}^{b} ; 0\right\} ; \max \left\{A_{1}^{a}-L_{1}^{a} ; 0\right\}\right\} .
$$

By construction, these capital transfers can preserve policyholder claims against the struggling subsidiary, but they cannot jeopardise the payment of claims by the supporting subsidiary. To explain how the capital transfers affect the subsidiaries' default ratios, we temporarily assume that $y^{(a)}, y^{(b)}, p^{(a)}, p^{(b)}, K^{(a)}$, and $K^{(b)}$ are fixed. Including the intra-group capital transfers, the default ratio of subsidiary $a$ is given by

$$
\begin{aligned}
d r^{a, \text { group }}= & \exp (-r) \mathbb{E}_{\mathbb{Q}}\left[\max \left\{L_{1}^{a}+Z_{1}^{a \rightarrow b}-A_{1}^{a}-Z_{1}^{b \rightarrow a}, 0\right\}\right] / L_{0}^{a} \\
= & \exp (-r) \mathbb{E}_{\mathbb{Q}}\left[\max \left\{L_{1}^{a}-A_{1}^{a}-Z_{1}^{b \rightarrow a}, 0\right\}\right] / L_{0}^{a} \\
= & \exp (-r) \mathbb{E}_{\mathbb{Q}}\left[\max \left\{L_{1}^{a}-A_{1}^{a}, Z_{1}^{b \rightarrow a}\right\}\right] / L_{0}^{a}-Z_{0}^{b \rightarrow a} / L_{0}^{a} \\
& \leqslant \exp (-r) \mathbb{E}_{\mathbb{Q}}\left[\max \left\{L_{1}^{a}-A_{1}^{a}, 0\right\}\right] / L_{0}^{a}-Z_{0}^{b \rightarrow a} / L_{0}^{a} \\
= & d r^{a, \text { stand-alone }}-Z_{0}^{b \rightarrow a} / L_{0}^{a},
\end{aligned}
$$

with $Z_{0}^{b \rightarrow a}=\exp (-r) \mathbb{E}_{\mathbb{Q}}\left[Z_{1}^{b \rightarrow a}\right] \geqslant 0$. The last equation illustrates the diversification effect in this context. If, in the future, $a$ becomes insolvent, and $b$ has available assets, the capital transfer $Z^{b \rightarrow a}$ has a positive time 0 value and intra-group capital transfers reduce the default ratio of subsidiary $a$. Vice versa, the same applies for the default ratio of subsidiary $b$. Hence, if capital transfers can take place in either direction at time 1, they lead to lower default ratios for both subsidiaries.

\section{Adjustment of the group's strategy}

How does the group adjust its pricing and capital structure in the presence of the diversification effect outlined by Eq. (7)? To answer this question, we now formulate the group's optimisation problem. Similar to Eq. (1), we can present the group's SHV as

$$
S H V^{\text {group }}=\sum_{i \in\{a, b\}}\left\{y^{(i)}\left(d r^{(i)}, p^{(i)}\right) \cdot\left[p^{(i)}-\mu^{(i)}\left(1-d r^{(i)}\right)\right]-\tau K^{(i)}\right\},
$$

where we denote the term in the curly brackets as the $S H V$ of subsidiary $i\left(S H V^{(i)}\right)$. Thus, we achieve the following equation for subsidiary $I$ 's premium (irrespective of whether the premium is optimal or not): ${ }^{33}$

\footnotetext{
${ }^{32}$ Gatzert and Schmeiser (2011).

${ }^{33}$ To arrive at this equation, note that the term in the curly brackets of Eq. (8) is denoted by $S H V^{(i)}$. Divide
} 


$$
p^{(i)}=\mu^{(i)}\left(1-d r^{(i)}\right)+\tau \cdot \frac{K^{(i)}}{y^{(i)}}+\frac{S H V^{(i)}}{y^{(i)}} .
$$

The group's optimisation problem is as follows:

$$
\left(P_{2}\right)\left(\begin{array}{l}
\sum_{i \in\{a, b\}} y^{(i)}\left(d r^{(i)}, p^{(i)}\right) \cdot\left[p^{(i)}-\mu^{(i)}\left(1-d r^{(i)}\right)\right]-\tau K^{(i)} \rightarrow \max _{K^{(a)}, K^{(b)}, p^{(a)}, p^{(b)}} \\
d r^{(a)}=\exp (-r) \mathbb{E}_{\mathbb{Q}}\left[\max \left\{L_{1}^{(a)}-A_{1}^{(a)}-Z_{1}^{b \rightarrow a}, 0\right\}\right] / L_{0}^{(a)} \\
d r^{(b)}=\exp (-r) \mathbb{E}_{\mathbb{Q}}\left[\max \left\{L_{1}^{(b)}-A_{1}^{(b)}-Z_{1}^{a \rightarrow b}, 0\right\}\right] / L_{0}^{(b)} \\
A_{0}^{(i)}=(1-\tau) K^{(i)}+y^{(i)}\left(d r^{(i)}, p^{(i)}\right) p^{(i)}, i=a, b \\
L_{0}^{(i)}=y^{(i)}\left(d r^{(i)}, p^{(i)}\right) \cdot \mu^{(i)}, i=a, b \\
K^{(a)}, K^{(b)}, p^{(a)}, p^{(b)} \geqslant 0
\end{array}\right.
$$

As the subsidies are legal entities, each with its own balance sheet, the group needs to decide how to allocate its capital at time 0 . In the formulation of $\left(P_{2}\right)$, this is done by choosing separate equity levels $K^{(a)}$ and $K^{(b)}$ at time 0 . Compared to capital allocation within an insurance company, ${ }^{9}$ which involves the problem of arbitrary choice of an allocation principle, ${ }^{17}$ capital allocation at the group level has "physical" consequences for the subsidies' balance sheets and is uniquely defined under the given objective function. An essential difference between this case and that of the standalone insurer is that the capital transfers $Z_{1}^{a \rightarrow b}$ and $Z_{1}^{b \rightarrow a}$ act as risk management instruments additional to raising capital.

An important aspect of this framework is that the capital transfers are contractually fixed at time 0 , which could be achieved, for example, via intra-group reinsurance contracts, guarantees, or profit and loss transfer agreements. Information intermediaries take the capital transfers into account when informing consumers about insurer default risk. Therefore, the capital transfers will influence insurance demand. Furthermore, a change in the premium or equity level at subsidiary $(a)$ will also affect the safety level, and thus insurance demand, at subsidiary $(b)$. This in turn influences the premium volume at subsidiary $(b)$ and also the capital transfer that flows from (b) to $(a)$. These circular relationships do not abolish the definition of problem $\left(P_{2}\right)$, but they do not permit solving the problem analytically, as could be done for the stand-alone insurer. We therefore derive solutions to the problem $\left(P_{2}\right)$ by numerical optimisation. 


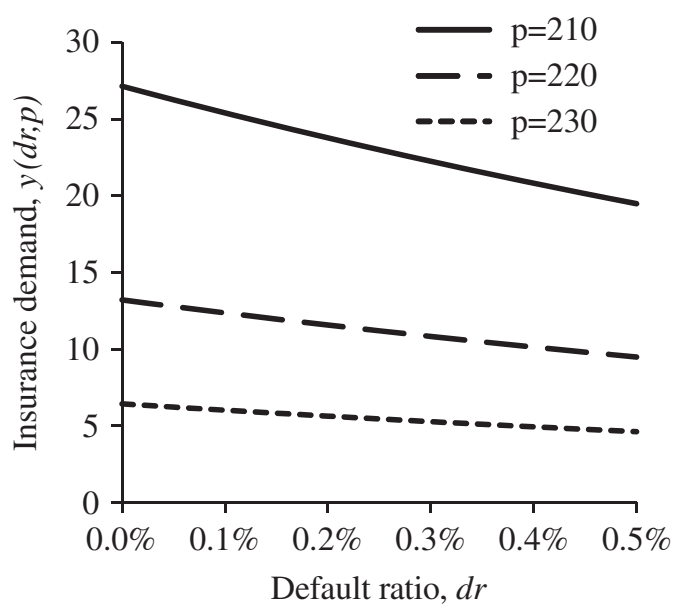

Figure 1. Insurance demand curve $y(d r, p)$ for $n=10^{8}, f_{p}=7.2$ per cent and $f_{d}=66.24$.

\section{Numerical example}

We will now use a numerical example to illustrate our results. In the following section, we will explain the model calibration and then present the results in the section "Optimal strategies".

\section{Model calibration}

To start with, we need to make a realistic assumption about the insurance demand function. The reaction of insurance demand to insurer default risk has been incorporated into several models before. ${ }^{34}$ For instance, the numerical examples in Gründl et al. ${ }^{35}$ and Yow and Sherris ${ }^{25}$ employ a linear relation between insurance demand and the insurer's default risk level, which however is not backed with empirical evidence. Zimmer et al. ${ }^{36}$ experimentally investigate insurance buyers' willingness to pay for insurance contracts having different levels of default risk. The authors also compare the experimentally obtained data against different types of insurance demand functions, including the linear function. The best fit for the data is an exponential demand function of the type

$$
y(p, d r)=n \cdot \exp \left(-f_{p} \cdot p-f_{d} \cdot d r\right) .
$$

In particular, Zimmer et al. ${ }^{36}$ find that this exponential function represents the data significantly better than a linear function. Figure 1 depicts the exponential insurance demand function depending on the default ratio for three different insurance

\footnotetext{
${ }^{34}$ Cummins and Sommer (1996), Cummins and Danzon (1997), Zanjani (2002), Gründl et al. (2006), Froot (2007) and Yow and Sherris (2008).

${ }^{35}$ Gründl et al. (2006).

${ }^{36}$ Zimmer et al. (2012).
} 
premiums. Clearly, insurance demand decreases in the default ratio, meaning that consumers' willingness-to-pay is lower for higher default risk levels. While the curves appear similar to linear functions, their slope is stronger the lower the default ratio is. This is in line with experimental evidence indicating that many policyholders reject insurance contracts even when they are subject to very small levels of default risk only. ${ }^{37}$ We will later use the following equations for the first-order derivatives of the exponential demand function:

$$
\begin{gathered}
\frac{y_{p}}{y}=-f_{p} \\
\frac{y_{d r}}{y}=-f_{d} \\
\frac{y_{d r}}{y_{p}}=\frac{f_{d}}{f_{p}}
\end{gathered}
$$

To model the insurer's asset and liability risks, we assume that the assets and liabilities evolve according to the stochastic processes under the risk-neutral measure $\mathbb{Q}$ :

$$
\begin{aligned}
& d A_{t}=r A_{t} d t+\sigma_{A} A_{t} d W_{A, t}^{\mathbb{Q}} \\
& d L_{t}=r L_{t} d t+\sigma_{L} L_{t} d W_{L, t}^{\mathbb{Q}}
\end{aligned}
$$

with $\sigma_{A}$ and $\sigma_{L}$ being the volatilities of the asset and liability processes, and $W_{A}^{\mathbb{Q}}, W_{L}^{\mathbb{Q}}$ geometric Brownian motions under $\mathbb{Q}$. We assume that the Brownian motions are correlated by $\rho_{A L}{ }^{38}$

We set the risk parameters to $\mu=200, \sigma_{A}=5$ per cent, $\sigma_{L}=20$ per cent, $\rho_{A L}=0$ per cent, ${ }^{39}$ which is consistent with the market-based calibrated model of Yow and Sherris. ${ }^{25}$ We assume for the frictional cost parameter $\tau=5$ per cent, which is reported to be an approximate value for the reinsurance industry (p. 298). ${ }^{7}$ For convenience, we assume $r=0$ per cent and set the market size parameter of the demand function to $n=10^{8} .{ }^{40}$ The price sensitivity parameter $f_{p}=7.2$ per cent corresponds to the results by

${ }^{37}$ Wakker et al. (1997), Zimmer et al. (2009).

${ }^{38}$ This assumption is consistent, for example, with Cummins and Sommer (1996), Cummins and Danzon (1997), Yow and Sherris (2008).

$39 \rho_{A L}=0 \%$ means that asset and liability risks are uncorrelated, which is in line with Yow and Sherris (2008, p. 309f.). Empirically, Cummins et al. (2006) find that the correlations between asset and liability risks vary strongly among different asset classes: for instance, long-term liability risks are negatively related to stocks, but positively related to government bonds or real estate investments. The correlations between insurance portfolios and the market portfolio have been found to be relatively small and often statistically insignificant in property-liability insurance (Fairley 1979; Cummins and Harrington 1985, 1988; Derrig 1994). Considering the market portfolio as a proxy for an insurer's asset portfolio, this justifies $\rho_{A L}=0 \%$.

40 Note that the demand function parameter $n$ does not affect the insurer's optimal default risk level and premium, since it is a merely a proportional factor in the problems $\left(P_{1}\right)$ and $\left(P_{2}\right)$. Therefore, the chosen value of $n$ only ensures that demand takes reasonable values under the insurer's optimal strategy. 
Table 1 Scenarios for composition of the insurance group

\begin{tabular}{llll}
\hline Scenario & \multicolumn{2}{c}{ Default sensitivity of demand $\left(f_{d}\right)$} & $\begin{array}{l}\text { Subsidiary } \\
\text { parameterisation }\end{array}$ \\
\cline { 2 - 4 } & Subsidiary $a$ & Subsidiary $b$ & symmetric \\
\hline I & Low $(33.12)$ & Low $(33.12)$ & symmetric \\
II & High $(66.24)$ & High $(66.24)$ & asymmetric \\
III & Low $(33.12)$ & High $(66.24)$ & asymm
\end{tabular}

Yow and Sherris (p. 318). ${ }^{25,41}$ As shown by Eq. (6), the optimal default ratio is determined by the ratio $y_{d r} / y_{p}$. In the experiment by Zimmer et al., (p. 16) ${ }^{36}$ in which participants had perfect information about insurer safety levels, this ratio was estimated to be about $y_{d r} / y_{p} \stackrel{E q .13}{=} f_{d} / f_{p} \approx 920$, which implies $f_{d}=7.2 \% \cdot 920=66.24$. Since this parameter is crucial for our analysis, we consider a second scenario with $y_{d r} / y_{p}=460$, that is, $f_{d}=7.2 \% \cdot 460=33.12$, reflecting a market in which there is less information available about insurer default risk. ${ }^{42}$ In the group case, we will consider three scenarios, which are presented in Table 1.

\section{Optimal strategies}

In the stand-alone case, we determine the optimal strategy by using the analytical solutions from the section "Optimal solution". We explain the calculation in more detail in the Appendix.

The first part of Table 2, consisting of the first two columns, presents the standalone insurer's optimal strategies under two different values for the default sensitivity of insurance demand. Comparing the first two columns of Table 2, we see that the optimal default ratio $d{ }^{*}$ is lower if default sensitivity of demand is high. With regard to the three insurance premium components, the payoffs to policyholders, $\mu \cdot\left(1-d r^{*}\right)$, as well as the frictional costs of equity endowment per insurance contract, $\tau \cdot K^{*} / y^{*}$, are higher in the second column due to the lower default ratio. The shareholder value per contract, $S H V^{*} / y^{*}$, is unaffected by the default ratio. ${ }^{43}$ In total, the optimal premium $p^{*}$ increases with the default sensitivity of demand. Insurance demand $y^{*}$ is lower if consumers are more sensitive to insurer default risk, and since shareholders' profits per contract are independent of $f_{d}{ }^{44} S H V^{*}$ is also lower for $f_{d}=66.24$.

${ }^{41}$ Under the optimal strategy, the price elasticity of demand equals $\varepsilon_{p}=-y_{p} / y / p \stackrel{E q .11}{=} f_{p} \cdot p=$ $7.2 \% \times 217.15=15.6$, which is in line with the empirical results in Yow and Sherris (2008, p. 318) for household or liability insurance.

42 The ratio between the scenarios with high default elasticity and low default elasticity, respectively, is simply $66.24 / 33.12=200 \%$. The empirical results from Yow and Sherris $(2008$, p. 318) suggest that the default elasticities of different lines of business can differ by a factor of up to 275 per cent.

${ }^{43}$ The reason for this is that due to Eq. (11), the profit loading on the premium (Eq. (4)) is a constant under the used insurance demand function.

${ }^{44}$ See Eq. (5). 
Sebastian Schlütter and Helmut Gründl

Table 2 Optimal strategies under different values for the default sensitivity of insurance demand $\left(f_{d}\right)$

\begin{tabular}{|c|c|c|c|c|c|c|}
\hline \multirow[t]{4}{*}{ Default sensitivity } & \multicolumn{2}{|c|}{ Stand-alone case } & \multicolumn{4}{|c|}{ Group case } \\
\hline & \multirow[b]{3}{*}{ Low } & \multirow[b]{3}{*}{ High } & \multirow{3}{*}{$\begin{array}{c}\text { Scenario I } \\
\text { Low }\end{array}$} & \multirow{3}{*}{$\begin{array}{c}\text { Scenario II } \\
\text { High }\end{array}$} & \multicolumn{2}{|c|}{ Scenario III } \\
\hline & & & & & Subsidiary a & Subsidiary $b$ \\
\hline & & & & & Low & High \\
\hline$f_{d}$ & 33.12 & 66.24 & 33.12 & 66.24 & 33.12 & 66.24 \\
\hline$d r^{*}$ & $0.47 \%$ & $0.16 \%$ & $0.30 \%$ & $0.10 \%$ & $0.35 \%$ & $0.07 \%$ \\
\hline$\mu \cdot\left(1-d r^{*}\right)$ & 199.07 & 199.67 & 199.41 & 199.80 & 199.29 & 199.87 \\
\hline$\tau \cdot K^{*} / y^{*}$ & 3.46 & 4.71 & 2.15 & 2.95 & 0.00 & 5.06 \\
\hline$S H V^{*} / y^{*}$ & 14.62 & 14.62 & 14.62 & 14.62 & 16.03 & 12.92 \\
\hline$P^{*}$ & 217.15 & 219.00 & 216.18 & 217.36 & 215.32 & 217.86 \\
\hline$y^{*^{\mathrm{a}}}$ & 13.90 & 12.73 & 15.76 & 14.93 & 16.45 & 14.75 \\
\hline$S H V^{* \mathrm{a}}$ & 203.15 & 186.11 & 230.57 & 218.27 & 263.70 & 190.75 \\
\hline
\end{tabular}

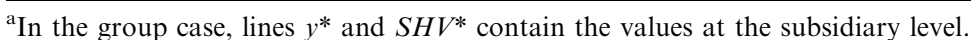

In Scenarios I and II of the group case, the strategies of Subsidiary $a$ and $b$ coincide. $\mu=200, \sigma_{A}=5 \%, \sigma_{L}=20 \%, \rho_{A L}=0 \%, \tau=5 \%, r=0 \%, n=10^{8}, f p=7.2 \%$.

In the group case, we do not have analytical solutions for the problem $\left(P_{2}\right)$; in particular, we cannot apply the results from the "Optimal solution" section. Therefore, we conducted a Monte-Carlo simulation with 5,000,000 runs and determined the group's optimal capital allocation $\left(K_{a}^{*}, K_{b}^{*}\right)$ and insurance premiums $\left(p_{a}^{*}, p_{b}^{*}\right)$ according to problem $\left(P_{2}\right)$ numerically. The default ratios of the subsidiaries, $d r_{a}^{*}, d r_{b}^{*}$, are determined by Eq. (7), and the numbers of concluded contracts follow from Eq. (10). Finally, the three premium components $\mu \cdot\left(1-d r^{*}\right), \tau \times K^{*} / y^{*}$, and $S H V^{*} / y^{*}$ correspond to Eq. (9).

The solutions for Scenarios I-III are depicted in the second part of Table 2 (columns 3-6). For Scenarios I and II, where the subsidiaries are symmetrically parameterised, we find that the group allocates its capital evenly to the subsidiaries and chooses identical safety levels and prices for both subsidiaries.

In Scenario I, the optimal default ratio decreases from 0.47 per cent in the standalone case to 0.30 per cent in the group case, due to intra-group risk diversification. Furthermore, the group has to hold less equity per insurance contract and thus saves on frictional costs. While the profit loading on the premium is not affected by the group-building and remains at 14.62, the group transmits its saved frictional costs to policyholders via a lower insurance premium. Together with the higher safety level, this induces a higher sales volume $y^{*}$ and implies that $S H V$ increases from 406.30 (both stand-alone insurers together) to 461.14 for the group.

In Scenario II, the group again achieves higher safety levels for its subsidiaries than in the stand-alone case. Interestingly, intra-group risk diversification has stronger effects on the required equity than in Scenario I, as frictional costs of equity per insurance contract decrease by 1.77 in Scenario II (Scenario I: -1.31). Due to the higher safety levels in Scenario II, it is more probable that a subsidiary can be bailed out with the group's remaining capital and therefore intra-group diversification is 
more effective. This implies that group-building has stronger effects on the premium reduction, the increase in sales volume, and also the increase in $S H V$ in Scenario II.

The last two columns of Table 2 present the results for Scenario III with asymmetric parameterisations for the subsidiaries. It is notable that the group optimally allocates all its equity to subsidiary $b$, where insurance demand is more default-sensitive (see line $\left.\tau \cdot K^{*} / y^{*}\right)$. Subsidiary $a$ does not hold any equity at all and its safety level is only ensured by means of the time-1-capital transfers from the other subsidiary. In fact, the equity endowment of zero is a corner solution because we did not allow for negative values of $K\left(\right.$ see $\left.\left(P_{2}\right)\right)$. Nevertheless, both subsidiaries achieve higher safety levels than the stand-alone insurers. The higher frictional costs of equity at subsidiary $b$ do not fully increase the insurance premium at this subsidiary, but are compensated for by a reduction of the profit loading (see line $S H V^{*} / y^{*}$ ). In turn, the group increases the profit loading at subsidiary $a$ and thereby finances the frictional costs of equity at the other subsidiary, which enables future capital transfers from subsidiary $b$ to $a$. Therefore, both the group's subsidiaries can attract more customers than in the standalone case, and group-building increases the $S H V$ from $203.15+186.11=389.26$ to $263.70+190.75=454.45$.

In total, we observe that the higher shareholder value in the group case essentially results from an increase of insurance demand. ${ }^{45}$ Intra-group risk diversification allows the group to offer insurance with less default risk at lower premiums. Therefore, there are more customers whose willingness-to-pay exceeds the insurance premium and the insurer can sell more contracts. We also note that shareholders' incentives for groupbuilding strongly depend on the parameterisation of the demand function and that they are higher when demand reacts strongly to default risk: with low default sensitivity of demand, group-building increases the SHV by 27.42 (or 13.5 per cent); with high default sensitivity, the increase is 32.16 (or 17.3 per cent).

\section{Welfare analysis}

The previous analyses have shown that intra-group risk diversification can be beneficial for shareholders as well as for policyholders. Compared to the standalone case, the group's value-maximising strategy implies a higher safety level and lower prices. This combination attracts more customers and thus increases shareholder value. However, empirical research indicates that mergers of financial firms frequently destroy shareholder value, often termed the "conglomerate discount". ${ }^{46}$ In theory, it is agency conflict between shareholders and managers that explains the conglomerate discount. $^{21}$ Since groups are more complex and opaque than smaller entities, shareholders could have reduced capacity for avoiding inefficient overinvestments or cross-subsidisation. We incorporate this aspect by letting the carrying charge $\tau$ differ between the stand-alone case $\tau^{s t . a}$ and the group case $\tau^{g r}$. All other parameters are taken from above (Scenario I). In addition to the results in Table 2,

\footnotetext{
${ }^{45}$ Note that the SHV per contract is completely unaffected by group-building in Scenarios I and II.

${ }^{46}$ Berger and Ofek (1995), Laeven and Levine (2007), Schmid and Walter (2009).
} 
Table 3 Optimal strategies in the group case with change in the carrying charge $\tau$ (Scenario I)

\begin{tabular}{|c|c|c|c|c|c|}
\hline \multirow[t]{2}{*}{ Organisation } & \multirow{2}{*}{$\frac{\text { Stand-alone }^{a}}{\tau^{\text {st.a }}=5 \%}$} & \multicolumn{4}{|c|}{ Group } \\
\hline & & $\tau^{g r}=5 \%$ & $\tau^{g r}=8 \%$ & $\tau^{g r}=9 \%$ & $\tau^{g r}=10 \%$ \\
\hline$d r^{*}$ & $0.47 \%$ & $0.30 \%$ & $0.48 \%$ & $0.54 \%$ & $0.61 \%$ \\
\hline$\mu \cdot\left(1-d r^{*}\right)$ & 199.07 & 199.41 & 199.04 & 198.91 & 198.79 \\
\hline$\tau \cdot K^{*} / y^{*}$ & 3.46 & 2.15 & 2.80 & 2.96 & 3.10 \\
\hline$S H V^{*} / y^{*}$ & 14.62 & 14.62 & 15.09 & 15.27 & 15.44 \\
\hline$p^{*}$ & 217.15 & 216.18 & 216.93 & 217.14 & 217.33 \\
\hline$y^{*}$ & 27.79 & 31.53 & 28.09 & 27.09 & 26.19 \\
\hline \multirow[t]{2}{*}{$S H V^{*}$} & 406.30 & 461.14 & 424.17 & 413.95 & 404.54 \\
\hline & & $(+54.84)$ & $(+17.87)$ & $(+7.65)$ & $(-1.76)$ \\
\hline \multirow[t]{2}{*}{$C S^{*}$} & 192.99 & 218.95 & 195.08 & 188.15 & 181.86 \\
\hline & & $(+51.91)$ & $(+4.17)$ & $(-9.68)$ & $(-22.27)$ \\
\hline
\end{tabular}

a The lines $S H V^{*}$ and $C S^{*}$ present the values of both stand-alone insurers in sum. $\mu=200, \sigma_{A}=5 \%, \sigma_{L}=20 \%, \rho_{A L}=0 \%, r=0 \%, n=10^{8}, f p=7.2 \%, f d=33.12$.

we measure policyholder value by the consumer surplus, which is defined by $C S(d r, p)=\int_{p}^{\infty} y(d r, \bar{p}) d \bar{p} \stackrel{E q .10}{=}(y(d r, p)) / f_{p} .{ }^{47}$

Table 3 presents the optimal strategies when $\tau$ changes after group-building from 5 percent to 8 per cent, 9 per cent, or 10 per cent. The results show that both the optimal default ratio and the insurance premium increase with a higher carrying charge $\tau^{g r}$, and hence the number of concluded contracts decreases. In all three cases, $\tau^{g r}=8$ per cent, 9 per cent, or 10 per cent, the default ratio is even higher than in the stand-alone case. For $\tau^{g r}=10$ per cent, the insurance premium is also higher than in the stand-alone case. Group-building is beneficial for shareholders if $\tau^{g r} \leqslant 9$ per cent, and destroys SHV for $\tau^{g r} \geqslant 10$ per cent. Policyholders are better off with the group if $\tau^{g r} \leqslant 8$ per cent, and worse off if $\tau^{g r} \geqslant 9$ per cent.

From a regulatory perspective, the case of $\tau^{g r}=9$ per cent is the most relevant one, because in this case shareholders would favour group-building, even though it destroys consumer surplus. The reasoning behind this result is that the insurer reacts to the higher carrying charge $\tau$ by demanding a higher profit loading on the premium $(S H V / y)$, which helps economise on costly equity. Together with $S H V / C S=f_{p} \cdot S H V / y,{ }^{48}$ this implies that the increase of $\tau^{g r}$ destroys more consumer surplus than shareholder value.

In the following, we generalise the results from Table 3 by considering different sets of parameters. Figure 2 depicts the combinations of the group's carrying charge $\tau^{g r}$ and the price sensitivity of demand $f_{p}$ in which group-building is beneficial or detrimental for shareholders or policyholders, respectively. According to Scenario I, we fix the default sensitivity of insurance demand to $f_{d}=33.12$. The figure shows that the interval of $\tau^{g r}$, in which shareholders benefit from group-building, but policyholders do not, becomes larger the smaller the price sensitivity of demand. If demand reacts weakly to price, the insurer finds it easier to substitute for costly equity by charging

\footnotetext{
${ }^{47}$ Stoyanova and Schlütter (2012).

48 This results from $S H V=\mathrm{y} \cdot(S H V / y)$ and $C S=\mathrm{y} \cdot\left(1 / f_{p}\right)$.
} 


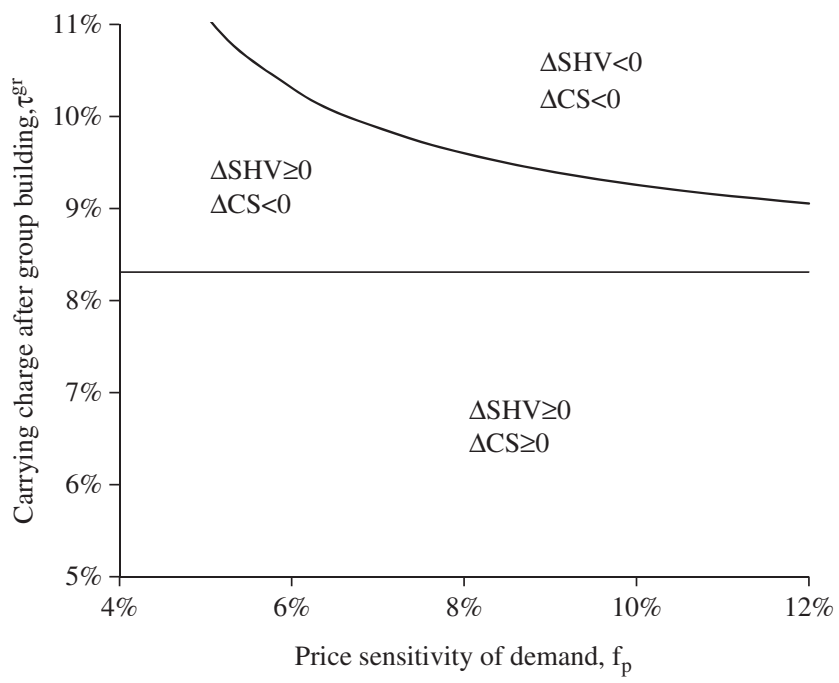

Figure 2. Areas in which group-building is beneficial/detrimental for shareholders or policyholders (Scenario I).

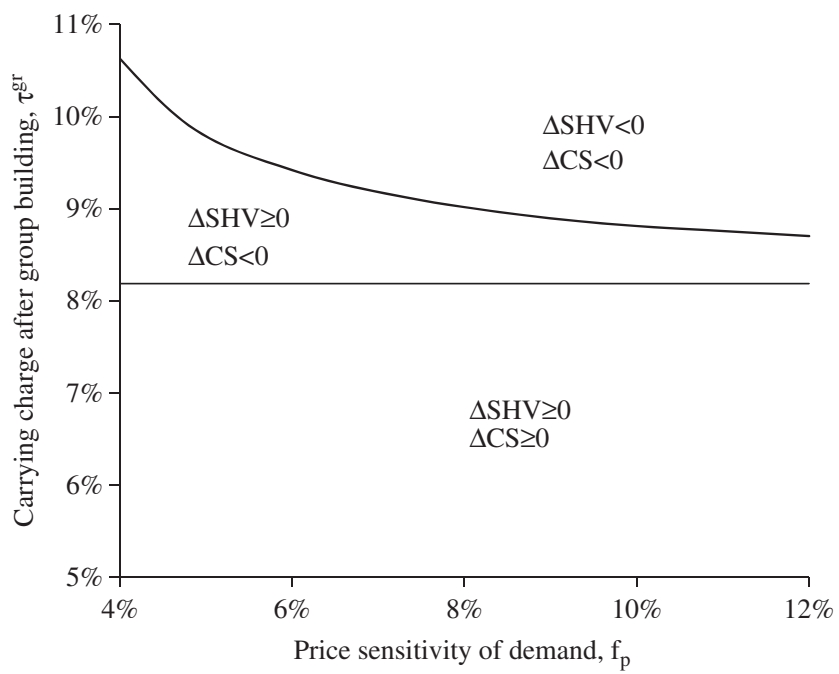

Figure 3. Areas in which group-building is beneficial/detrimental for shareholders or policyholders (Scenario II).

higher premiums and thus avoiding the frictional costs of equity. In turn, if the price sensitivity of demand becomes high, insurers cannot demand an essential profit margin on the premium and have less latitude in replacing equity with premiums. Figure 3 transfers the results to Scenario II. We see that the "problematic" area in which only shareholders benefit from group-building is smaller than in Figure 2. Due to the higher default sensitivity of demand, the group cannot adjust the subsidiaries' default ratios as much as in Scenario I. ${ }^{49}$ 


\section{Discussion}

With regard to shareholders' benefits from insurance group-building, both the theoretical and the empirical literature provide heterogeneous results. On the one hand, risk diversification between the group's entities can reduce the sum of the group's required capital. ${ }^{50}$ Assuming that holding capital is costly, this would imply that group-building benefits shareholders. ${ }^{51} \mathrm{On}$ the other hand, there are several theoretical arguments that group-building is disadvantageous for shareholders. The disadvantages result from a reduction in the group's cash flow volatility, which reduces the value of shareholder claims, ${ }^{52}$ and from additional agency costs due to the higher complexity of groups. ${ }^{21}$

This paper combines the two lines of reasoning by balancing the diversification benefits against the higher dead-weight costs of holding equity capital. Our results are important for insurance supervision. Up to now, there have been few studies on measuring welfare effects from group-building on policyholders. ${ }^{53}$ On the basis of the existing literature, it is not clear whether policyholders could lose value by consolidation, whether shareholders could provoke such situations based on their own incentives, and thus whether supervisory authorities should be concerned about group-building activities from a consumer protection perspective.

Our results suggest that group-building can be detrimental for policyholders if the group faces a higher carrying charge for holding capital than the stand-alone insurers. Such a situation is likely when the group finds it much harder to communicate its risk profile to shareholders and thus faces additional expenses for measuring and reporting the risks in its entities as well as the group-wide risk diversification. This problem can be especially severe when group-building takes place across different jurisdictions (e.g. between an EU and non-EU country), or across different business models (e.g. life and non-life insurance). We demonstrate that there are situations in which group-building is also detrimental for shareholders, meaning that shareholders might be willing to prevent the grouping. This case may occur if demand depends strongly on the price for insurance and/or on insurer default risk. Therefore, competition and transparency could help to avoid group formations, which are disadvantageous from the perspective of policyholders. The empirical findings by Yow and Sherris (p. 318 $)^{25}$ suggest that these conditions are rather satisfied in commercial lines (particularly in fire insurance) and rather unsatisfied in personal lines or in compulsory third party insurance. In the latter cases, that is when consumers care little about solvency or about price, it is possible that shareholders profit from group-building while policyholders suffer.

To compare the optimal strategies of stand-alone insurers and groups, the paper uses a simplified model set-up that could be extended in several directions. An important issue for future research would be to incorporate a higher number of subsidiaries. By doing so, the question arises how intra-group capital transfers at

\footnotetext{
49 Adjustment of the default ratio in scenario I is documented in line $d r^{*}$ of Table 3 .

${ }^{50}$ Filipović and Kupper (2008).

${ }^{51}$ Smith and Stulz (1985), Froot (2007).

${ }^{52}$ Mansi and Reeb (2002).

${ }^{53}$ Freixas et al. (2007), Gatzert and Schmeiser (2011).
} 
time 1 should be arranged, and the approach by Filipović and Kupper ${ }^{1}$ could be useful in finding a solution. Since capital transfers help the group to attract a larger number of customers and save frictional costs of equity, we expect that it would be optimal for the group to arrange transfers, which use all available assets to bail out struggling subsidiaries. The definition of an optimal net of capital transfers could therefore be simplified to finding an optimal ranking order in which subsidiaries are supported if more than one should get into financial distress. Besides, large groups face a more complex problem of allocating their equity at time 0 to the subsidiaries. Insurance risk managers' lack of ability (or willingness) to attain an optimal intra-group capital allocation is another explanation for increasing agency costs in large insurance groups.

Our results depend on the assumptions that the group can credibly commit on future capital transfers among its entities and that policyholders take this commitment into account when making their purchase decision. On the one hand, it seems reasonable that the group could find ways to fix this commitment, for example by means of internal reinsurance contracts. To present a realistic view of the insurer's risk profile, rating agencies and regulators might take these contracts into account, and their consequences would thus also be apparent for policyholders. If regulators do not fully account for internal capital transfers, for example because the subsidiaries operate in different regulatory jurisdictions, it is conceivable that the group seeks to commit on the aspired risk transfer by means of external reinsurance or alternative risk transfer arrangements. On the other hand, the question arises of whether it is in the group's self-interest to fix contractually the complete use of future available capital for bail-outs. In a multi-period context, the group could prefer to decide ad hoc whether to use all available capital for rescuing distressed subsidiaries or to let them go bankrupt, focus on other investment opportunities and continue the business with the financially sound subsidiaries only. Without the group's commitment, it will be much more difficult for regulators, rating agencies, and policyholders to forecast the effectiveness of intra-group capital transfers in advance. In an extreme case, that is when policyholders' willingness to pay does not react to intra-group capital transfers at all, the group must endow the subsidiaries with equity capital as if they were standalone insurers. However, the empirical analysis by Zanjani ${ }^{54}$ suggests that reputation might induce groups to rescue struggling subsidiaries even in the absence of binding contracts, and it seems likely that the market participants anticipate this chance at least in part. In total, it should be recognised that the group's decision on an optimal capital transfer arrangement is strongly affected by contagion and reputation risks.

Finally, our paper stresses that more research should be undertaken to identify the shape and the parameter size of the price-default-demand function. We have shown that shareholders' incentives for insurance group-building as well as the likelihood that shareholders will advocate a merger which is destructive to consumer welfare strongly depend on the sensitivities of insurance demand. To forecast the welfare of insurance groups, it is therefore necessary to have knowledge of the shape and parameterisation of insurance demand functions in different insurance branches.

\footnotetext{
${ }^{54}$ Zanjani (2009).
} 


\section{Conclusion}

This paper analyses insurance groups' optimal equity capital levels and insurance premiums and compares them to those optimal for stand-alone insurers. We first demonstrate the stand-alone insurers' optimal solutions based on an analytical formula. We then generalise the model with regard to a simplified insurance group. We show that the group engages in intra-group risk diversification by adjusting its safety levels and insurance prices. As long as group-building does not affect the carrying charge for holding equity, it is beneficial for consumers as well as for shareholders.

However, if the group's diversity and complexity increases the dead-weight cost of equity capital, insurer default risk and premiums both could be higher for the group than for the stand-alone insurer. We show that an increase in dead-weight costs has even more severe consequences for consumer surplus than for shareholder value. Hence, situations can occur in which shareholders would support group-building even though doing so will be detrimental for consumers. This stresses the importance of insurance group supervision acting on behalf of consumer protection.

The paper can also be seen as a contribution to the literature on capital allocation in insurance companies. In previous articles, certain capital allocation methods are investigated to what extent they meet certain axiomatic requirements. ${ }^{55}$ In our approach, we endogenise capital allocation by determining the optimal equity capital at the subsidiary level by shareholder-value-maximisation and thus find an economic foundation for group-wide capital allocation.

The paper also provides a basis for further empirical work. If it is possible to attribute certain parameter settings, such as price and default sensitivities, to certain insurance lines of business, we would have a theoretical basis for hypothesizing on possible benefits and drawbacks of insurance group-building. To this end, the numerical analyses in this paper provide first insights on the interdependence between insurance demand functions, frictional costs of capital, and group-building welfare effects.

\section{Acknowledgements}

We thank two anonymous referees as well as the seminar participants at Humboldt University of Berlin, University of St. Gallen, Goethe University Frankfurt, the International Congress of Insurance: Mathematics and Economics (Toronto, Canada), the World Risk and Insurance Economics Congress (Singapore), the WU Competence Day (Vienna, Austria), and the Annual Meeting of the German Insurance Science Association (Hanover, Germany) for their helpful comments.

\section{References}

Amihud, Y. and Lev, B. (1981) 'Risk reduction as a managerial motive for conglomerate mergers', Bell Journal of Economics 12(2): 605-618.

Ammann, M. and Verhofen, M. (2006) 'The conglomerate discount: A new explanation based on credit risk', International Journal of Theoretical and Applied Finance 9(8): 1201-1214.

Aron, D.J. (1988) 'Ability, moral hazard, firm size, and diversification', The RAND Journal of Economics 19: $72-87$.

\footnotetext{
55 Denault (2001), Myers and Read (2001).
} 
Berger, P. and Ofek, E. (1995) 'Diversification's effect on firm value', Journal of Financial Economics 37(1): 39-65.

Berry-Stölzle, T.R., Hoyt, R.E. and Wende, S. (2011) 'Capital market development, competition, property rights, and the value of insurer product-line diversification: A cross-country analysis', Journal of Risk and Insurance, 41 p. 41.

Cummins, J.D. (1988) 'Risk-based premiums for insurance guaranty funds', Journal of Finance 43(4): 823-839.

Cummins, J.D. and Danzon, P.D. (1997) 'Price, financial quality, and capital flows in insurance markets', Journal of Financial Intermediation 6(1): 3-38.

Cummins, J.D. and Harrington, S.E. (1985) 'Property-liability insurance regulation: Estimation of underwriting betas using quarterly profit data', Journal of Risk and Insurance 52(1): 16-42.

Cummins, J.D and Harrington, S.E. (1988) 'The relationship between risk and return: Evidence for property-liability insurance stocks', Journal of Risk and Insurance 55(1): 15-31.

Cummins, J.D and Sommer, D.W. (1996) 'Capital and risk in property-liability insurance markets', Journal of Banking and Finance 20(6): 1069-1092.

Cummins, J.D., Lin, Y. and Phillips, R.D. (2006) An empirical investigation of the pricing of financially intermediated risks with costly external finance, Wharton Financial Institutions Center 06-13, p. 48.

Cummins, J.D., Weiss, M.A. and Zi, H. (2003) Economies of scope in financial services: A DEA bootstrapping analysis of the U.S. insurance industry, Working Paper, Wharton Financial Institutions Center, p. 60.

Denault, M. (2001) 'Coherent allocation of risk capital', Journal of Risk 4(1): 5-34.

Derrig, R.A. (1994) 'Theoretical considerations of the effect of federal income taxes on investment income in property-liability ratemaking', Journal of Risk and Insurance 61(4): 691-709.

Doherty, N.A. and Garven, J.R. (1986) 'Price regulation in property-liability insurance: A contingent claims approach', Journal of Finance 41(5): 1031-1050.

Fairley, W. (1979) 'Investment income and profit margins in property-liability insurance: Theory and empirical tests', Bell Journal of Economics 10(1): 192-210.

Filipović, D. and Kupper, M. (2008) 'Optimal capital and risk transfers for group diversification', Mathematical Finance 18(1): 55-76.

Freixas, X., Ĺóranth, G. and Morrison, A.D. (2007) 'Regulating financial conglomerates', Journal of Financial Intermediation 16(4): 479-514.

Froot, K. (2007) 'Risk management, capital budgeting, and capital structure policy for insurers and reinsurers', Journal of Risk and Insurance 74(2): 273-299.

Gatzert, N. and Schmeiser, H. (2008) 'The influence of corporate taxes on pricing and capital structure in property-liability insurance', Insurance: Mathematics and Economics 42(1): 50-58.

Gatzert, N. and Schmeiser, H. (2011) 'On the risk situation of financial conglomerates: Does diversification matter?' Financial Markets and Portfolio Management 25(1): 3-26.

Gründl, H., Post, T. and Schulze, R.N. (2006) 'To hedge or not to hedge: Managing demographic risk in life insurance companies', Journal of Risk and Insurance 73(1): 19-41.

Gründl, H. and Schmeiser, H. (2002) 'Pricing double-trigger reinsurance contracts: Financial versus actuarial approach', Journal of Risk and Insurance 69(4): 449-468.

Gründl, H. and Schmeiser, H. (2007) ‘Capital allocation for insurance companies - What good is it?' Journal of Risk and Insurance 74(2): 301-317.

Hull, J.C. (2009) Options, Futures and Other Derivatives, $7^{\text {th }}$ edition, New Jersey: Prentice Hall.

Ibragimov, R., Jaffee, D.M. and Walden, J. (2010) 'Pricing and capital allocation for multiline insurance firms', Journal of Risk and Insurance 77(3): 551-578.

Jensen, M. (1986) 'Agency costs of free cash flow, corporate finance, and takeovers', American Economic Review 76(2): 323-329.

Jensen, M. and Murphy, K. (1990) 'Performance pay and top-management incentives', Journal of Political Economy 98(2): 225-264.

Keller, P. (2007) 'Group diversification', The Geneva Papers on Risk and Insurance-Issues and Practice 32(3): 382-392.

Laeven, L. and Levine, R. (2007) 'Is there a diversification discount in financial conglomerates?' Journal of Financial Economics 85(2): 331-367. 
Luder, T. (2007) 'Modelling of risks in insurance groups for the Swiss Solvency Test', Bulletin of the Swiss Association of Actuaries 1: 85-97.

Mansi, S.A. and Reeb, D.M. (2002) 'Corporate diversification: What gets discounted?' Journal of Finance 57(5): 2167-2183.

Margrabe, W. (1978) 'The value of an option to exchange one asset for another', Journal of Finance 33(1): $177-186$

Merton, R.C. (1997) 'A model of contract guarantees for credit-sensitive, opaque financial intermediaries', European Financial Review 1: 1-13.

Modigliani, F. and Miller, M.H. (1958) 'The cost of capital, corporation finance and the theory of investment', The American Economic Review 48(3): 261-297.

Myers, S.C. and Read, J.A. (2001) 'Capital allocation for insurance companies', Journal of Risk and Insurance 68(4): 545-580.

Phillips, R., Cummins, J. and Allen, F. (1998) 'Financial pricing of insurance in the multiple-line insurance company', Journal of Risk and Insurance 65(4): 597-636.

Rees, R., Graveller, H. and Wambach, A. (1999) 'Regulation of insurance markets', Geneva Papers on Risk Insurance. Theory 24(1): 55-68.

Rotemberg, J.J. and Saloner, G. (1994) 'Benefits of narrow business strategies', American Economic Review 84(5): 1330-1349.

Schlütter, S. (2011) Capital requirements or pricing constraints? An economic analysis of measures for insurance regulation, Working paper, Goethe University Frankfurt, p. 35.

Schmid, M.M. and Walter, I. (2009) 'Do financial conglomerates create or destroy economic value?' Journal of Financial Intermediation 18(2): 193-216.

Smith, C.W.J. and Stulz, R.M. (1985) 'The determinants of firms' hedging policies', Journal of Financial and Quantitative Analysis 20(4): 391-405.

Stoyanova, R. and Schlütter, S. (2012) Safety versus affordability as targets of insurance regulation in an opaque market: A welfare approach, Working paper, Goethe University Frankfurt, p. 32.

Stulz, R.M. (1990) 'Managerial discretion and optimal financing policies', Journal of Financial Economics 26(1): 3-27.

Wakker, P.P., Thaler, R.H. and Tversky, A. (1997) 'Probabilistic insurance', Journal of Risk and Uncertainty 15(1): 7-28.

Yow, S. and Sherris, M. (2008) 'Enterprise risk management, insurer value maximisation, and market frictions', Astin Bulletin 38(1): 293-339.

Zanjani, G. (2002) 'Pricing and capital allocation in catastrophe insurance', Journal of Financial Economics 65(2): 283-305.

Zanjani, G. (2009) On the paradoxical relation between group support and subsidiary insolvency in the insurance industry, Working paper, Georgia State University, p. 15.

Zimmer, A., Gründl, H. and Schade, C. (2012) Be as safe as possible: A behavioral approach to the optimal corporate risk strategy of insurers, Working paper, Goethe University Frankfurt, p. 41.

Zimmer, A., Schade, C. and Gründl, H. (2009) 'Is default risk acceptable when purchasing insurance? Experimental evidence for different probability representations, reasons for default, and framings', Journal of Economic Psychology 30(1): 11-23.

\section{Appendix}

The Appendix provides analytical solutions for the default ratio and the optimal assetliability ratio in the stand-alone case. Moreover, it explains how to calculate the standalone insurer's optimal strategy. We price shareholders' future cash flow by employing option pricing theory as proposed by Doherty and Garven, ${ }^{16}$ Cummins, ${ }^{56}$ Cummins and Sommer, ${ }^{57}$ and Cummins and Danzon. ${ }^{24}$ In these models, shareholders' default

\footnotetext{
${ }^{56}$ Cummins (1988).

${ }^{57}$ Cummins and Sommer (1996).
} 
put option is understood as a put option on the time-1 equity position. Under the assumption that the asset and liability processes evolve according to geometric Brownian motions, the default ratio can be determined by using Margrabe's ${ }^{58}$ solution for the value of an exchange option: ${ }^{59}$

$$
\begin{gathered}
d r(s, \sigma)=\Phi(z)-s \cdot \Phi(z-\sigma), \\
\sigma=\sqrt{\sigma_{A}^{2}+\sigma_{L}^{2}-2 \rho_{A L} \sigma_{A} \sigma_{L}}, \\
z=\frac{-\ln (s)}{\sigma}+\frac{1}{2} \sigma,
\end{gathered}
$$

where $\Phi$ denotes the distribution function of the standard normal distribution. Since $d r(s, \sigma)$ increases strictly monotonically and is continuously differentiable in $s$, the inverse $s(d r, \sigma)$ is well defined and continuously differentiable in $d r$.

Under the given assumptions, the insurer's optimal asset-liability ratio (see Eq. (6)) can be provided in a closed form: ${ }^{31}$

$$
s^{*}(\sigma)=\exp \left(-\sigma \cdot \Phi^{-1}\left[\frac{\mu}{f_{d} / f_{p}-(1-\tau) \mu}\right]-\frac{\sigma^{2}}{2}\right),
$$

with $\Phi^{-1}$ being the quantile function of the standard normal distribution. The equation is derived by balancing the benefit from a higher asset-liability ratio, that is higher insurance demand, against the corresponding costs, such as a lower default put option value and higher frictional costs of equity. The components on the right-hand side comprise all the parameters that influence this trade-off, that is particularly the volatility of the insurer's portfolio, the demand function parameters and the carrying charge of holding equity.

For the scenario with low default sensitivity $\left(f_{d}=33.12\right)$, the results can be calculated as follows:

\footnotetext{
58 Margrabe (1978).

${ }^{59}$ For example, Myers and Read (2001, p. 553), Gatzert and Schmeiser (2008, p. 53), Yow and Sherris (2008, p. 314) and Gatzert and Schmeiser (2011, p. 8). For a further explanation of the components of Eq. (14), see Hull (2009, pp. 566-567 and 291-294).
} 


$$
\begin{gathered}
\sigma \stackrel{E q .15}{=} \sqrt{5 \%^{2}+20 \% 0^{2}} \approx 0.2062 \\
s^{*}(0.2062) \stackrel{E q .17}{=} \exp \left(-0.2062 \cdot \Phi^{-1}\left[\frac{200}{33.12 / 7.2 \%-0.95 \cdot 200}\right]-\frac{0.2062^{2}}{2}\right) \approx 1.4148 \\
z \stackrel{E q .16-\ln (1.4148)}{0.2062}+\frac{1}{2} \cdot 0.2062 \approx 1.5800 \\
d r^{*} \stackrel{E q .14}{=} \Phi(1.58)-1.4148 \cdot \Phi(1.58-0.2062) \approx 0.4654 \% \\
\mu \cdot\left(1-d r^{*}\right)=200 \cdot(1-0.4654) \approx 199.07 \\
\tau \cdot K^{*} / y^{*} \stackrel{E q .3}{=} 5 \% \cdot\left[200 \cdot 1.4148-200 \cdot(1-0.4654 \%)-\frac{1}{1-5 \%} \cdot \frac{1}{7.2 \%}\right] \approx 3.46 \\
S H V^{*} / y^{*} \stackrel{E q .5}{=} \frac{1}{1-5 \%} \cdot \frac{1}{7.2 \%} \approx 14.62 \\
p^{*} \stackrel{E q .4}{=} 199.07+3.46+14.62 \approx 217.15 \\
y^{*} \stackrel{E q .10}{=} 10^{8} \cdot \exp (-7.2 \% \cdot 217.15-33.12 \cdot 0.4654) \approx 13.90 \\
S H V^{*}=\frac{S H V^{*}}{y^{*}} \cdot y^{*}=14.62 \cdot 13.90 \approx 203.15
\end{gathered}
$$

\section{About the Authors}

Sebastian Schlütter studied business mathematics at Ulm University with a focus on operations research and actuarial science. After working for 2 years as a consultant at zeb/rolfes.schierenbeck.associates, he joined the Dr. Wolfgang Schieren Chair of Insurance and Risk Management at Humboldt University of Berlin in 2009 as a research assistant and took up his doctoral studies. Since 2010 he has been with the International Center for Insurance Regulation at Goethe University Frankfurt. His research interests include insurance risk management and insurance regulation.

Helmut Gründl holds the Chair of Insurance and Regulation at Goethe University in Frankfurt and is the managing director of the International Center for Insurance Regulation (ICIR), which is sponsored by the German Insurance Association (GDV) and the State of Hesse. From 1999 to 2010 he held the Chair for Insurance and Risk Management at Humboldt University of Berlin. His research interests cover all aspects of insurance regulation, risk management, insurance pricing and capital allocation. 